\title{
A comunicação e a cultura no cotidiano
}

\begin{abstract}
RESUMO
Há supremacia do campo midiológico em relação ao cotidiano? Esta é a questão que (re)convocamos no presente estudo ao invertermos o eixo tradicional teórico do problema, entendendo a comunicação e a cultura cotidianas como aspectos relevantes a serem considerados pelas mídias. Cultura aqui, assim como informação, é entendida como um bem público, um direito da coletividade que precisa de significação.
\end{abstract}

\section{PALAVRAS-CHAVE}

- mídias

- comunicação

- cotidiano

\section{ABSTRACT}

Is there a supremacy of the mass-media field over everyday life? This is the question we (re)introduce in this study by inverting the traditional theoretical axis of the problem, understanding everyday communication and culture as aspects relevant to be considered by mass media. Culture, like information, is understood like a public right, a right of collectivity that needs signification.

\section{KEY WORDS}

- media

- communication

- everyday life

\section{Wellington Pereira \\ UFPB}

0 nosso objetivo é, inicialmente, inverter a lógica do debate no sentido "naturalista", no qual um campo de saber, cujos códigos são legitimados socialmente, aparece em supremacia, no sentido axiológico, em relação a outros. Neste sentido, cultura e comunicação, seriam campos de maior importância do que o cotidiano, de acordo com uma "arqueologia" das ciências humanas e sociais; considerando os padrões utilitários e racionais das ciências modernas.

Em outra perspectiva, poderíamos pensar invertendo a lógica das hermenêuticas, como a comunicação e as mídias procuram se apropriar dos aspectos estéticos e filosóficos do cotidiano, através de leituras preferenciais. ${ }^{1}$

De algum modo, a quebra da hegemonia da cultura sobre a comunicação e destas sobre o cotidiano, em se tratando da análise dos fenômenos culturais, tem sido mais evidenciada pelos pedagogos e antropólogos; menos pelos sociólogos e teóricos da comunicação. Estes, na maioria, presos a esquemas tautológicos responsáveis pela perpetuação de modelos comunicacionais que não interagem com a complexidade dos movimentos sociais.

Para alargar nossa compreensão, poderíamos construir a seguinte questão: para que servem a cultura e a comunicação na vida cotidiana?

\section{$\mathbf{0}$ cotidiano e as culturas}

De acordo com Michel Maffesoli: “... o cotidiano não é um conceito que se pode, mais ou menos utilizar na área intelectual. É um estilo no sentido [...] de algo mais abrangente, de ambiente, que é a causa e o efeito, em determinado momento, das relações sociais em seu conjunto [...] De tudo o que foi dito, devese lembrar que o estilo pode ser considerado, stricto sensu, uma encarnação ou ainda a projeção concreta de todas as atitudes emocionais, maneiras de pensar e agir, em suma, de todas as relações com o outro, pelas quais se define uma cultura". ${ }^{2}$

Nesta primeira assertiva, partindo da citação de Michel Maffesoli, podemos dizer que há dois momentos, nos quais a cultura e a comunicação começam a interagir com o cotidiano:

1. O problema da alteridade? O reconhecimento do outro;

2. As maneiras de agir e pensar dos indivíduos.

Neste segundo ponto, temos a aproximação do cotidiano como espaço de produção de fatos sociais, a partir do conceito de Durkheim: "É fato social toda maneira de agir fixa ou não, suscetível de exercer sobre o indivíduo uma coerção exterior; ou então, 
ainda, que é geral na extensão de uma sociedade dada, apresentando uma existência própria, independente das manifestações individuais que possa ter". ${ }^{3}$

\section{"é preciso, sobretudo, pensar a cotidianidade em relação ao imaginário social de cada povo: as riquezas estéticas traduzidas nos ritmos, nas imagens e na fala"}

No primeiro ponto, se faz necessário verificar se é possível estender o conceito de estilo às formas cotidianas. Assim, evitaremos pensar o estilo como algo pessoal, mas estabelecido nas tribos e comunidades.

Para não cair na armadilha positivista "o estilo é o homem", preferimos utilizar o conceito de formismo sociológico, tomado emprestado a Simmel. Neste sentido, podemos pensar a forma como a "gramaticalidade do invisível" que liga signos de diferenças semânticas e estabelece territórios sintáticos capazes de dialogar entre si, estabelecendo o formismo social.

Maffesoli define o formismo como “(...) um polípode que tem implicações estéticas, éticas, econômicas, políticas, e, evidentemente, gnosiológica". ${ }^{4}$

As formas na vida cotidiana têm a função de ligar os fatos sociais, através da sinergia ou das sinestesias produzidas por cada cidadão. Assim, os indivíduos geram fatos sociais, de acordo com a anomia estabelecida em cada momento sociocultural, e, ao mesmo tempo, reconhecem as alteridades de outras formas culturais.

Dirimindo as distâncias entre fato social e formas sociais, podemos afirmar que a cultura e a comunicação não estão fora da cotidianidade, o que significa o modus como os autores sociais qualificam os objetos do imaginário. Em outras palavras, a reversibilidade do taedium vitae? O tédio da vida? Em manifestações estéticas.

Para efeitos didáticos, poderíamos estabelecer três elementos constitutivos da vida cotidiana:

1. O mundo da vida;

2. A vida cotidiana;

3. A cotidianidade.

O mundo da vida é um conceito caro a fenomenologia de Alfred Schutz. Ele designa o mundo intersubjetivo que existe antes do nosso nascimento. Portanto, devemos observar as heranças socioculturais constituídas em nosso imaginário. ${ }^{5}$ Há de se considerar o caráter de "estocagem" do conhecimento adquirido na luta pela sobrevivência.
A partir da metade do século XIX, o conceito de vida cotidiana aparece em consonância com a descrição de mundo civilizado "Esta vida cotidiana se manifesta como um dos temas centrais, primeiro nas pesquisas sobre saúde pública, como as realizadas pelo médico Villermé, em seguida no plano sociológico por Le Play, na França, e Dilthey, na Alemanha" ${ }^{6}$

Não é demasiado afirmar que o conceito de vida cotidiana, num primeiro momento, se debruça sobre as condições de vida dos trabalhadores, das condições objetivas da produção capitalista, como: "O trabalho forçado, a falta de repouso, a ausência de cuidados, a insuficiência e a má qualidade da alimentação, a embriaguez, atitudes de imprudência, desordens, assim como os salários abaixo das necessidades reais". ${ }^{7}$

A cotidianidade é a qualidade, a adjetivação dos procedimentos da vida cotidiana. Na sociedade de consumo, a cotidianidade pode se confundir com bem-estar material, produção de bens simbólicos, luxo "gaspillage" (desperdício). É preciso, sobretudo, pensar a cotidianidade em relação ao imaginário social de cada povo: as riquezas estéticas traduzidas nos ritmos, nas imagens e na fala. Isto é o que faz com que a vida cotidiana não seja igual para grupos sociais, mesmo que estes ocupem o mesmo espaço urbano.

Ao elegermos a cotidianidade como umas das formas qualitativas da vida cotidiana, estaremos contrariando a assertiva de Henri Lefebvre: "A história do cotidiano compreenderia pelo menos três partes: estilos; o fim dos estilos e o começo da cultura (século XIX); a instalação e a consolidação da cotidianidade, que mostraria como o cotidiano se cristaliza, há mais de um século, com o fracasso de cada tentativa revolucionária $(. . .)^{\prime \prime} .8$

\section{A comunicação na vida cotidiana e o problema das disjunções semânticas}

Um dos problemas de representação da vida cotidiana nas mídias é o ser caráter disjuntivo. Ou seja, as editorias de cidades ou gerais? Algumas têm como título "cotidiano"? Mostram o dia-a-dia dos cidadãos através de uma lógica da irrupção social. Os fatos cotidianos aparecem isolados dos estatutos sociais e das forças estético-ideológicas empreendidas na luta pela ocupação dos espaços na sociedade.

O cotidiano das camadas periféricas dos grandes centros urbanos é sempre o que não deu certo, o fracasso de uma atitude social, ou mesmo, a demonstração da exclusão dos indivíduos do processo de "modernização", como uma ameaça aos "vencedores" que já ultrapassaram os conceitos da modernização e podem usufruir da "livre" circulação de bens simbólicos.

Há uma mudança nos cenários sociais que favorece à "desregulamentação" do social em detrimento 
de um novo modelo de sociedade: a sociedade do medo. E o medo é a grande mercadoria que a informação midiática embrulha em formatos narrativos para ser exibida no cotidiano.

O medo é vendido através da sofisticação tecnológica, o que exige do seu mercado consumidor a constante agregação de acessórios ao modus vivendi (muros altos com cercas elétricas, cães de guarda, humanos ou não, sistema panóptico). Deste modo, a leitura dos jornais, os olhares sobre as reportagens televisuais, a escuta do noticiário radiofônico podem comprovar que o difícil é viver a vida cotidiana. Mas por quê? Porque a informação midiática é inversamente proporcional ao ideal comunitário.

O ideal comunitário resiste na vida cotidiana, a partir de redes semânticas capazes de tornar viáveis ações imperceptíveis no cotidiano, mas importantes na manutenção dos imaginários sociais.

As redes semânticas são tecidas na vida cotidiana pela sintaxe de vários autores, que ocupam espaços diferentes e são responsáveis pela produção de diversas formas estéticas, do sublime ao grotesco. Mas são imperceptíveis pelos construtos da sociedade da informação. Por quê? A reposta deve seguir três vias de interpretação:

1. A epistemologia da vida cotidiana;

2. As disjunções cotidianas;

3. O problema da comunicação no cotidiano.

A epistemologia da vida cotidiana se constrói no reconhecimento de saberes fora dos círculos institucionais, diretamente responsáveis pela conexão de formas sociais que dão impulsos às atitudes dos atores sociais. São os saberes que não se polarizam entre doxa (senso comum) e episteme (conhecimento sistematizado), mas buscam unir as contradições das novas formas de convivência social.

Ao procurar entender as interconexões dos saberes na vida cotidiana, o pesquisador se depara com um dos principais desafios: o efêmero. Mas, ao invés de tomar os fenômenos cotidianos como algo que se "esfuma" na moldura dos processos discursivos, é preciso pensar que estes micros saberes (a desconfiança, a reação passiva, a afirmação do dito pelo não-dito) fazem parte, na maioria das vezes de uma estratégia de "gastar" o tempo para dominá-lo.

Os micro-saberes são formas de organizações táteis, visuais e sensoriais que demarcar os territórios socioculturais nos quais os poderes se exercem. Eles são anteriores a uma microfísica do poder, pois, necessariamente, não determinam uma ordem.

Este "saberes banais" estabelecem um fluxo de relações socioestéticas que, através do oxímoro ou das metáforas provocam o jogo das alteridades sem a violência da dominação, utilizando o riso, a pantomima, as gingas, tatuagens? Pensamos aqui em todas as possibilidades lúdicas corpo? Para desestabi- lizar a institucionalização dos momentos em ambiências formais: no púlpito, na escola.

\section{Os micro-saberes e o politeísmo da vida cotidiana}

Os saberes cotidianos se configuram através do efêmero. Englobam os campos da religiosidade, das estéticas e dos prazeres, mas, sobretudo, de uma ética do "devir", na qual o indivíduo é respeitado, em sua comunidade, por sua capacidade de produzir blagues, trocadilhos, glosas em relação aos discursos factuais e institucionalizados socialmente. Estes atores podem ser bêbados, poetas, prostitutas, vagabundos. Eles dominam os signos escondidos na arquitetura do banal.

O importante é pensar a comunicação, nesta construção de uma epistemologia do cotidiano, como um recurso para entendermos que: “[...] há polaridades que reúnem atitudes e sentimentos e que, em suas tensões conflituais, constituem toda estruturação social" ${ }^{9}$

\section{As disjunções cotidianas}

A forma como a vida cotidiana se apresenta na mídia, por exemplo, guarda as marcas das disjunções sociais. Neste sentido, o cotidiano é o espaço por excelência das fragmentações, dos atos não concretizados de acordo com as tensões entre o espaço público e o campo jornalístico.

\section{"o nosso conflito começa neste abismo entre a técnica de informar e as estratégias de comunicação que se estabelecem na vida cotidiana"}

Para Bourdieu, um campo "é um espaço social estruturado, um campo de forças, permanentes, de desigualdades, que se exercem no interior desse espaço? Que é também um campo de lutas para transformar ou conservar esse campo de forças". ${ }^{10}$

Em oposição às assertivas de Bourdieu, podemos pensar que a vida cotidiana veiculada pelas mídias não é apenas um reflexo de campos configurados para a manutenção de poderes institucionalizados. Estes são constituídos pela linguagem das mídias que preferem ocultar as forças sociais divergentes para "doar" aos leitores liberdades "linguageiras", democracias "descritivas".

Mas o que destacamos aqui como uma armadilha montada para o campo jornalístico é que a vida cotidiana foge ao enquadramento do social pela sociedade. E isto é quase que imperceptível quando se pensa as comunidades através das mídias. 
O problema é que a aplicabilidade de teorias sobre a vida cotidiana é, em geral, realizada de forma vertical. Nem sequer chegamos a alcançar os níveis analíticos dos tipos ideais weberianos, mas partimos de um "lócus" absoluto, no qual os principais elementos de caracterização do cotidiano dos grandes centros urbanos são: a pobreza econômica, o aniquilamento das diferenças étnicas, a baixa taxa de escolaridade, a precariedade da saúde pública, a violência sexual Para garantir a visibilidade dos desencaixes sociais, as mídias, especificamente os jornais impressos, vão utilizar o substantivo feminino violência como o conceito geral capaz de reunir todas as anomalias sociais.

Mas, nesta doxa da violência ou da violência da doxa, não são contempladas outras formas de violência, como o "terrorismo cognitivo", ou seja, a capacidade de distorção de conceitos históricos, a manipulação das palavras em prol de ajustes socioeconômicos e ideológicos.

Evidentemente, mostrar o cotidiano como algo incompleto? Desde o buraco na rua, a longa fila de bancos, o desespero dos aposentados do INSS nos postos de saúde, o aumento hodierno dos combustíveis, a ineficiência do ensino? É uma estratégia de manutenção de um Estado que aceita a sociedade e rejeita o social.

Negar o social em detrimento da sociedade é empobrecer o caráter epistemológico da vida cotidiana e as múltiplas possibilidades de os seus agentes produzirem intervenções e mudanças inusitadas.

Nesta investigação dos fenômenos produzidos no cotidiano, os produtores de linguagens (jornalistas, publicitários, cineastas, relações públicas, bacharéis em turismo) devem ultrapassar estas injunções sociais impostas ao nosso dia-a-dia e procurar entender, como diz Georg Simmel "a profunda aparência da vida cotidiana". ${ }^{11}$

\section{Os problemas da comunicação e da cultura na vida cotidiana}

Para podermos compreender a comunicação na vida cotidiana é sugerimos pensar nesta proposição de Georg Simmel: "Todos os eventos banais, exteriores, são finalmente, ligados por fios condutores às opções finais, referentes ao sentido e ao estilo de vida". ${ }^{12}$

Como o predomínio é dos sistemas informacionais, das comunidades em rede, há um deslocamento da principal função da comunicação: reconquistar o caráter antropológico e social das comunidades.

Uma das primeiras denúncias da perda da função comunitária da comunicação foi feita por Walter Benjamin em seu ensaio O narrador. ${ }^{13}$

Evidentemente, a preocupação de Benjamin, acerca da forma pela qual se constrói a narrativa na contemporaneidade, nos traz implicações da ordem sociocultural, mas também não deixa de nos alertar para a substituição das narrativas tradicionais por técnicas informacionais. Este é um dos principais problemas de reconhecimento do imaginário da vida cotidiana: o estabelecimento de uma comunicação vertical, mediada por ferramentas eletrônicas com ênfase nas imagens.

O não reconhecimento da complexidade da vida cotidiana, na sociedade pós-moderna, ocorre pelo caráter instrumental da informação, do preenchimento dos vazios sociais pela quantidade e pela comercialização de conteúdos que não respeitam a alteridade, as diferenças culturais e recriam contextos históricos artificiais.

A vida cotidiana, sem a efetivação dos processos comunicativos, fica mais confusa, e o grau de separação entre os homens? A proxemia? Aumenta.

Para alguns pesquisadores existe um fosso entre o desenvolvimento tecnológico e o processo comunicativo, como afirma Dominique Wolton: "Essa defasagem entre a facilidade da Comunicação Técnica e a dificuldade da Comunicação Humana é a primeira razão pra que se construa uma teoria da comunicação. O canal não basta para criar a relação. É preciso compreender as razões da defasagem entre a eficiência da condição técnica e a dificuldade da comunicação humana e social". ${ }^{14}$

O nosso conflito começa neste abismo entre a técnica de informar e as estratégias de comunicação que se estabelecem na vida cotidiana.

Do ponto de vista da aluvião de informação, temos a ilusão do suprimento das lacunas socioculturais através da difusão de mensagens, no menor espaço de tempo possível, com a aceleração do tempo social.

Nesse sentido, o conhecimento passa a depender da capacidade de deslocamento e estocagem de signos. Isto é a função da "comunicação midiática".

A comunicação midiática se define pela antecipação das realidades através das tecnologias. E aqui não se trata de polarizar a discussão sobre as novas tecnologias à maneira de apocalípticos ou integrados, mas de pensar os processos comunicacionais a partir da vida cotidiana, ao contrário das teorias vigentes que pensam o cotidiano a partir da superposição de conceitos.

É proveitoso tomar como alerta esta afirmação de Dominique Wolton: "O mais fácil, na comunicação, ainda são as ferramentas; o mais complicado, os homens e a sociedade. Mesmo que amanhã houvesse 6,5 bilhões de internautas, isto não bastaria para garantir a paz entre as civilizações, as sociedades, as culturas e as religiões". ${ }^{15}$

Evidentemente, estamos enfatizando a função pedagógica da comunicação, que pode ser apreendida nas formas da vida cotidiana, como afirma Wolton: "Na verdade o desafio da comunicação não é a gestão das semelhanças, mas a gestão das diferenças". ${ }^{16}$

Agora, podemos estabelecer o nosso desafio:

1. Pensar a comunicação e a cultura a partir da vida cotidiana; 
2. Verificar os signos a vida cotidiana independente de modelos culturais e comunicacionais formulados a priori.

O conceito de cultura que nos interessa é o do complexo mundo do cotidiano, no qual predominam: a concepção de movimento, a interferência e mudanças no mundo tido como natural (isto vale para a aceitação passiva das novas tecnologias), sem cairmos no paralelismo clássico dos conceitos de civilização e cultura. ${ }^{17}$

Se alguns autores consideram que "a comunicação é fundamentalmente um problema do campo da cultura" ${ }^{18}$ isto deve ser resolvido na leitura das epistemologias do cotidiano.

Hoje, um expressivo número de teóricos da cultura e da comunicação, não haveria sentido falarmos do retorno de "um modelo comunicacional Torre de Babel", pois a máquinas tradutoras venceram as guerras hermenêuticas.

O problema é que a Torre de Babel, no campo das comunicações e das culturas, não se estabelece mais na verticalização dos paradigmas, dos modelos, obviamente saturados pela razão. O perigo está na construção de babéis a partir do eixo sintagmático, horizontal, na incapacidade de organizar tanta informação sem um tempo social para interpretação.

Assim, iniciamos a era da Babel sintática, perdendo, cada vez mais, o poder de organizar os significados? Não apenas no sentido normativos? Mas sem capacidade para entender a natureza da cultura, como nos explicita Clifford Geertz: "A cultura é pública porque o significado o é" ${ }^{19}$

Se a cultura é o bem público, ela deve ser pensada a partir dos signos da comunicação que se configuram como sistema reticular na vida cotidiana:

Rede sutil, complexa, na qual cada elemento, objeto, assunto, situação anódinas, eventos importantes, pensamento, ação, relação, etc., só funcionam enquanto ligado ao todo e só faz sentido dentro e pela globalidade. É isso que se percebe, de uma maneira mais ou menos consciente, na valorização contemporânea do quotidiano. Sente-se em correspondência com os outros, participa-se, com os outros, de um conjunto mais vasto".$^{20}$ aAMEcos

\section{NOTAS}

1. HALL, Stuart. Da diáspora - identidades e mediações culturais. Belo Horizonte: UFMG, 2003. p. 366.

2. MAFFESOLI, Michel. A contemplação do mundo. Porto Alegre: Artes e Ofícios, 1985. p. 64.

3. DURKHEIM, Émile. Durkheim: Sociologia. São Paulo: Ática, 2003. p. 52.
4. MAFFESOLI, Michel. O conhecimento comum. São Paulo: Brasiliense, 1985. p. 111.

5. SCHUTZ, Alfred. Fenomenologia e Relações Sociais. Rio de Janeiro: Zahar , 1979. p. 72.

6. JUAN, Salvador. Les formes élémentaires de la vie quotidienne. Paris: Puf, 1991. p. 20.

7. Ibidem, p. 21.

8. LEFEBVRE, Henri. A vida cotidiana no mundo moderno. São Paulo: Ática, 1991. p.86.

9. MAFFESOLI, Michel. O conhecimento comum, op. cit. p.219.

10. BOURDIEU, Pierre. Sobre a Televisão. Rio de Janeiro: Jorge Zahar, 1997. p. 57.

11. SIMMEL, Georg apud MAFFESOLI. O conhecimento comum; op. cit; p.213.

12. SIMMEL, Georg, apud Maffesoli, A contemplação do mundo; op. cit, p.65.

13. BENJAMIN, Walter. Magia e técnica, arte e política. São Paulo: Brasiliense, 1985.p.197.

14. WOLTON, Dominique. Pensar a comunicação. Brasília: Editora da Universidade de Brasília, 2004 p. 15.

15. Idem, p. 15.

16. Idem, ibidem, p.17

17. EDGAR, Andrew et al. Teoria Cultural de A a Z - conceitos-chave para entender o mundo contemporâneo. São Paulo: Contexto, 2003. p75.

18. LOPES, Luiz Carlos. O culto às mídias - interpretação, cultura e contratos. São Carlos: Editora da Universidade de São Carlos, 2004 p.34.

19. GEERTZ, Clifford. A interpretação das culturas. Rio de Janeiro: LTC, 1989 p.22.

20. MAFFESOLI, Michel. A contemplação do mundo, op. cit.p. 65. 